\title{
Blunt Traumatic Aortic Injury: 10-Year Single-Center Experience
}

\author{
Ahmet Can Topcu, MD ${ }^{1}$ Kamile Ozeren-Topcu, MD ${ }^{1}$ \\ Avni U. Seyhan, MD ${ }^{3}$ Ilyas Kayacioglu, MD ${ }^{1}$
}

Ahmet Bolukcu, MD ${ }^{1}$ Sinan Sahin, $\mathrm{MD}^{2}$

Address for correspondence Ahmet Can Topcu, MD, Department of Cardiovascular Surgery, Dr. Siyami Ersek Thoracic and Cardiovascular Surgery Training and Research Hospital, Selimiye Mh. Tibbiye Cd. No: 13, 34668 Uskudar, Istanbul, Turkey (e-mail: ahmet.topcu@icloud.com).

\begin{abstract}
Keywords

- aorta

- endovascular

- surgery

- thoracic

- trauma

Objective In blunt trauma patients, injury of the thoracic aorta is the second most common cause of death after head injury. In recent years, thoracic endovascular aortic repair (TEVAR) has largely replaced open repair as the primary treatment modality, and delayed repair of stable aortic injuries has been shown to improve mortality. In light of these major advancements, we present a 10-year institutional experience from a tertiary cardiovascular surgery center.

Methods Records of patients who underwent endovascular or open repair of the ascending, arch or descending thoracic aorta between January 2009 and December 2018 were retrospectively analyzed. Patients without blunt traumatic etiology were excluded. Perioperative data were retrospectively collected from patient charts. Longterm follow-up was performed via data from follow-up visits and phone calls.

Results A total of 1,667 patients underwent 1,740 thoracic aortic procedures (172 TEVAR and 1,568 open repair). There were 13 patients (12 males) with a diagnosis of blunt thoracic aortic injury. Mean patient age was 43.6 years (range, $16-80$ years). Ten (77\%) patients underwent TEVAR, two (15.4\%) underwent open repair, and one (7.7\%) was treated nonoperatively. Procedure-related stroke was observed in one $(7.7 \%)$ case. Procedure-related paraplegia did not occur in any patients. Left subclavian artery origin was covered in seven patients. None developed arm ischemia. Hospital survivors were followed-up for an average of 60.2 months (range, 4-115 months) without any late mortality, endoleak, stent migration, arm ischemia, or reintervention.

Conclusion Blunt thoracic aortic injury is a rare but highly fatal condition. TEVAR offers good early and midterm results. Left subclavian artery coverage can be performed without major complications.
\end{abstract}

\section{Introduction}

In blunt trauma patients, injury of the thoracic aorta is the second most common cause of death after head injury. ${ }^{1,2} \mathrm{Up}$ to $85 \%$ of patients with blunt thoracic aortic injury (BTAI) die at the scene or during transfer to a medical facility. ${ }^{1-3}$ of those who reach hospital alive, $50 \%$ die before aortic repair can be performed. ${ }^{2}$

The landmark study by Parmley and colleagues ${ }^{4}$ in 1958 demonstrated the high mortality associated with BTAI. Since received

February 3, 2020

accepted after revision

June 20, 2020

published online

March 24, 2021
DOI https://doi.org/

$10.1055 / \mathrm{s}-0040-1715608$.

ISSN 2325-4637.
(C) 2021. The Author(s).

This is an open access article published by Thieme under the terms of the Creative Commons Attribution License, permitting unrestricted use, distribution, and reproduction so long as the original work is properly cited. (https://creativecommons.org/licenses/by/4.0/)

Thieme Medical Publishers, Inc., 333 Seventh Avenue, 18th Floor, New York, NY 10001, USA 
then, management of patients with BTAI has gone through some major advancements. With widespread availability of multidetector scanners, computed tomography angiogram (CTA) has replaced plain chest X-ray as a screening tool and aortogram as a diagnostic tool. ${ }^{5,6}$ Following the first report of endovascular treatment of BTAI with custom devices, thoracic endovascular aortic repair (TEVAR) has largely replaced open repair as the primary treatment modality. ${ }^{5-8}$ Delayed repair of stable aortic injuries has been shown to improve mortality. ${ }^{5,6,9}$ In light of these major advancements in the diagnosis and management of BTAI, we present 10 -year institutional experience from a tertiary cardiovascular surgery center.

\section{Materials and Methods}

\section{Patients}

The study design was approved by Institutional Research Ethics Committee. All procedures related to the study were conducted in accordance with the ethical standards of the Helsinki Declaration. Individual consent was waived due to the retrospective nature of the study. Records of patients who underwent endovascular or open repair of the ascending, arch or descending thoracic aorta between January 2009 and December 2018 were retrospectively analyzed. A total of 1,667 patients underwent 1,740 thoracic aortic procedures (172 TEVAR and 1,568 open repair). Patients without blunt traumatic etiology were excluded. All trauma patients were referred with a diagnosis of BTAI from other medical facilities for cardiovascular intervention. Perioperative data were retrospectively collected from patient charts.

\section{Initial Management}

Patients were admitted to a dedicated cardiovascular surgery intensive care unit (ICU). Meticulous intravenous fluid replacement was administered with care to avoid "hyperresuscitation." Intravenous esmolol infusion was used to maintain systolic blood pressure below $120 \mathrm{~mm} \mathrm{Hg}$. Where esmolol was insufficient, intravenous nitrates were started.

\section{Imaging}

CTA of the chest, head, and neck was used for aortic measurements, injury grading, and preoperative planning (-Fig. 1). Severity of aortic injury was classified according to clinical practice guidelines of the Society for Vascular Surgery (SVS): grade I, intimal tear; grade II, intramural hematoma; grade III, aortic pseudoaneurysm; and grade IV, free rupture. ${ }^{10,11}$ Cerebral vascular anatomy was assessed for possible left subclavian artery (LSA) coverage.

\section{Intervention}

Patients underwent TEVAR if they were suitable candidates. The decision between TEVAR and open repair was made based on anatomical location of aortic injury, patient's vascular anatomy, concomitant injuries, and hemodynamics, and availability of an endovascular device.

Endovascular procedures were performed in a dedicated catheterization laboratory under general anesthesia. Vascu-

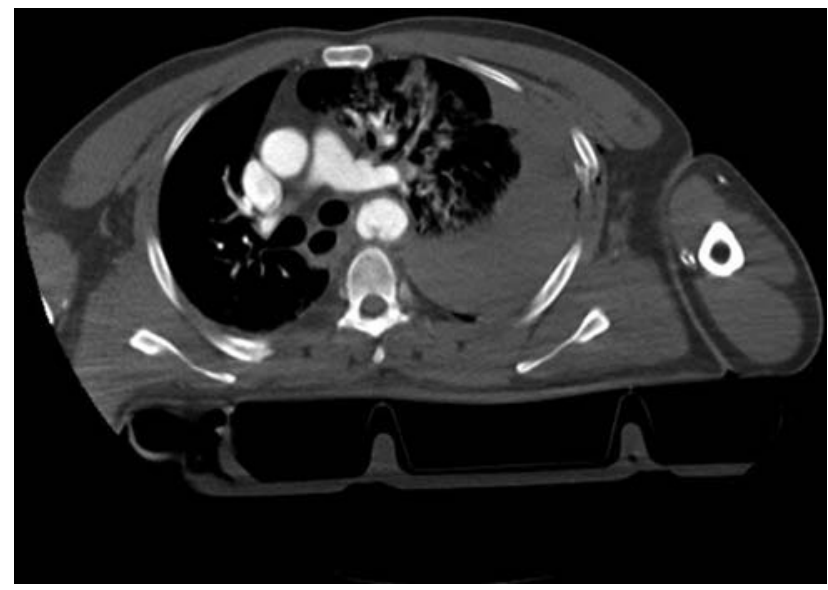

Fig. 1 Computed tomography angiogram demonstrating aortic isthmus pseudoaneurysm, mediastinal hematoma and left hemothorax after blunt trauma.

lar access was gained using open femoral artery exposure. Routine arch aortogram was performed. Patients received low-dose systemic heparin. LSA origin was covered if necessary to obtain adequate proximal seal. Protamine was given for heparin reversal.

Patients unsuitable for TEVAR underwent open repair. Operations were performed under general anesthesia using extracorporeal circulation through sternotomy, left thoracotomy, or sternothoracotomy with full-dose heparin. Cerebrospinal fluid drainage was used where necessary. Protamine was given for anticoagulation reversal.

\section{Outcome and Follow-up}

All survivors returned to ICU. Following cardiovascular stabilization, patients were either discharged home or referred to other facilities for treatment of their concomitant injuries. Patients who underwent TEVAR were followed up with CTA at 1,6 , and 12 months after procedure (-Fig. 2). Long-term follow-up was performed via data from follow-up visits and phone calls.

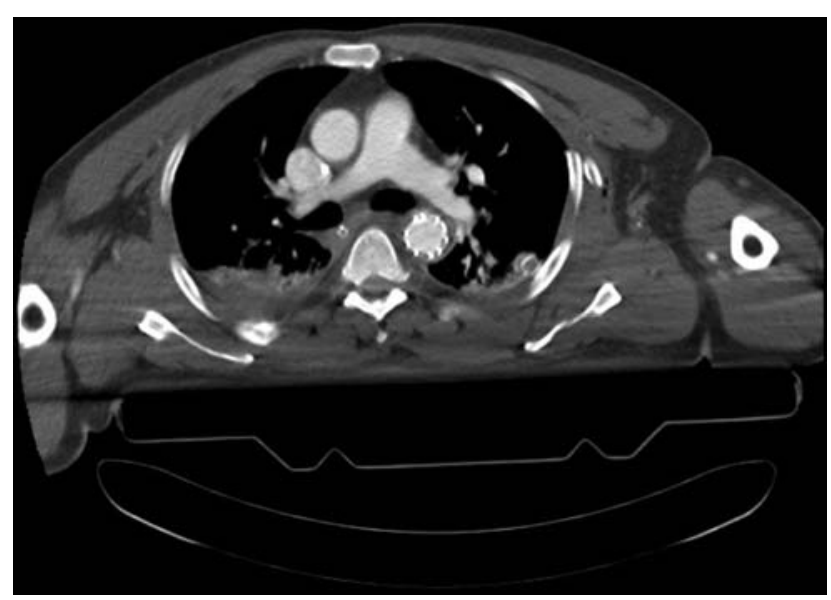

Fig. 2 Follow-up computed tomography angiogram after endovascular repair for blunt thoracic aortic injury. 
Table 1 Patient demographics

\begin{tabular}{|l|l|l|}
\hline Characteristic & \multicolumn{1}{|l|}{$N$} & $\%$ \\
\hline $\begin{array}{l}\text { Age (y) } \\
\text { Mean (range) }\end{array}$ & \multicolumn{2}{|l|}{$43.6(16-80)$} \\
\hline Male & 12 & 92.3 \\
\hline Trauma mechanism: & 5 & 38.5 \\
\hline Motor vehicle collision & 4 & 30.8 \\
\hline Fall from height & 2 & 15.4 \\
\hline Motorcycle collision & 1 & 7.7 \\
\hline Pedestrian hit by vehicle & 1 & 7.7 \\
\hline Crushed under falling object & 1 & 30.8 \\
\hline $\begin{array}{l}\text { Hypotension on admission } \\
\text { (SBP } \leq 90 \text { mm Hg) }\end{array}$ & 4 & 38.5 \\
\hline GCS $<15$ on admission & 5 & \\
\hline $\begin{array}{l}\text { GCS } \\
\text { Mean (range) }\end{array}$ & 11.8 (3-15) \\
\hline $\begin{array}{l}\text { ISS } \\
\text { Mean (range) }\end{array}$ & 32.3 (16-48) \\
\hline
\end{tabular}

Abbreviations: GCS, Glasgow coma scale; ISS, injury severity score; SBP, systolic blood pressure.

\section{Results}

Thirteen patients (12 males) with a diagnosis of BTAI were treated in our institution between January 2009 and December 2018. Mean patient age was 43.6 years (range, 16-80 years). The most common mechanism of injury was motor vehicle collision ( $n=5,38.5 \%$ ), followed by fall from height $(n=4, \quad 30.8 \%)$. Hypotension (systolic blood pressure $\leq 90 \mathrm{~mm} \mathrm{Hg}$ ) was present in four (30.8\%) patients. Five (38.5\%) patients had Glasgow coma scale (GCS) $<15$ on admission. Mean injury severity score (ISS) was 32.3 (range, 16-48; - Table 1 ).

Nine (69.2\%) patients underwent TEVAR, two (15.4\%) underwent open repair and one (7.7\%) underwent TEVAR followed by open repair (-Table 2). One patient was managed nonoperativelly, and eventually developed a chronic pseudoaneurysm at isthmus level and a juxtarenal coarctation caused by abdominal surgery for liver injury. This patient was treated with a successful hybrid procedure 5 years after the index trauma. LSA origin was covered in seven patients. None developed left arm ischemia. Excluding one patient with ascending aortic injury, mean diameter of the healthy aorta proximal to injury was $26.7 \mathrm{~mm}$ (range, 19$36.8 \mathrm{~mm}$ ). Mean stent diameter and length were $27.4 \mathrm{~mm}$ (range, 22-36 mm) and $124 \mathrm{~mm}$ (range, $80-150 \mathrm{~mm}$ ), respectively. Mean interval between admission and intervention was 33.7 hours (range, 3.5-95.7 hours). Six patients underwent delayed repair (repair $>24$ hours; - Table 2 ).

There were two (15.4\%) in-hospital deaths. One death was aortic related, and the other was caused by sepsis. Among hospital survivors, mean duration of mechanical ventilation was 257.8 hours (range, 2-2112 hours), mean ICU length of stay (LOS) was 15.6 days (range, 1-89 days), and mean hospital LOS was 29.3 days (range, 2-105 days). One patient
Table 2 Operative details

\begin{tabular}{|c|c|c|}
\hline Characteristic & $N$ & $\%$ \\
\hline \multicolumn{3}{|l|}{ Type of aortic intervention: } \\
\hline TEVAR & 9 & 69.2 \\
\hline Open repair & 2 & 15.4 \\
\hline TEVAR followed by open repair & 1 & 7.7 \\
\hline NOM & 1 & 7.7 \\
\hline LSA coverage: & 7 & - \\
\hline $\begin{array}{l}\text { Aortic diameter proximal to injury (mm) } \\
\text { Mean (range) }{ }^{\mathrm{a}}\end{array}$ & \multicolumn{2}{|c|}{$\begin{array}{l}26.7 \\
(19-36.8)\end{array}$} \\
\hline $\begin{array}{l}\text { Stent diameter (mm) } \\
\text { Mean (range) }\end{array}$ & \multicolumn{2}{|c|}{$\begin{array}{l}27.4 \\
(22-36)\end{array}$} \\
\hline $\begin{array}{l}\text { Stent length }(\mathrm{mm}) \\
\text { Mean (range) }\end{array}$ & \multicolumn{2}{|c|}{$\begin{array}{l}124 \\
(80-150)\end{array}$} \\
\hline \multicolumn{3}{|l|}{ Surgical incision: } \\
\hline Thoracotomy & 1 & - \\
\hline Sternotomy & 1 & - \\
\hline Sternothoracotomy & 1 & - \\
\hline \multicolumn{3}{|l|}{ Perfusion technique: } \\
\hline Total CPB & 2 & - \\
\hline Left heart bypass & 1 & - \\
\hline $\begin{array}{l}\text { Interval between admission } \\
\text { and intervention (h) } \\
\text { Mean (range) }\end{array}$ & \multicolumn{2}{|c|}{$\begin{array}{l}33.7 \\
(3.5-95.7)\end{array}$} \\
\hline Delayed repair ( $>24$ hours) & 6 & - \\
\hline
\end{tabular}

Abbreviations: CPB, cardiopulmonary bypass; LSA, left subclavian artery; NOM, nonoperative management; TEVAR, thoracic endovascular aortic repair.

${ }^{a}$ Excluding one patient with ascending aortic injury.

experienced post-TEVAR aortic rupture, and was successfully treated with replacement of the descending aorta through a left posterolateral thoracotomy using left heart bypass. There were three (23.1\%) patients with stroke and three (23.1\%) with paraplegia. Stroke was procedure-related in one (7.7\%). Other stroke cases were due to concomitant head injuries. All three patients with paraplegia had concomitant spinal cord and/or thoracolumbar spine injury, and were paraplegic on admission. Hospital survivors were followed-up for an average of 60.2 months (range, 4-115 months) without any late mortality, endoleak, stent migration, arm ischemia, or reintervention (-Table $\mathbf{3}$ ).

Diagnosis was made by means of CTA in all patients. Aortic isthmus was the most common site of injury ( $n=12$; - Fig. 3A and $\mathbf{B})$. There were two (15.4\%) SVS grade-IV injuries, four (30.8\%) grade-III injuries, six (46.2\%) grade-II injuries, and one (7.7\%) grade-I injury (-Table 4 ). Two patients with grade-IV aortic injuries presented in extremis with cardiac tamponade. They both underwent emergency open repair with total CPB. One of them had a free rupture of the proximal ascending aorta, and underwent a Bentall's procedure with mechanical valved conduit through a sternotomy. He had an underlying ascending aortic aneurysm with a diameter of $55 \mathrm{~mm}$. 
Table 3 Postoperative course

\begin{tabular}{|c|c|c|}
\hline Detail & $N$ & $\%$ \\
\hline In-hospital mortality: & 2 & 15.4 \\
\hline Aortic-related mortality & 1 & 7.7 \\
\hline $\begin{array}{l}\text { Duration of mechanical ventilation (hours) } \\
\text { Mean (range) }\end{array}$ & \multicolumn{2}{|c|}{$\begin{array}{l}257.8 \\
(2-2112)\end{array}$} \\
\hline $\begin{array}{l}\text { Intensive care unitlength of stay (d) } \\
\text { Mean (range) }{ }^{\mathrm{a}}\end{array}$ & \multicolumn{2}{|c|}{$\begin{array}{l}15.6 \\
(1-89)\end{array}$} \\
\hline $\begin{array}{l}\text { Hospital length-of-stay }(\mathrm{d}) \\
\text { Mean (range) }\end{array}$ & \multicolumn{2}{|c|}{$\begin{array}{l}29.3 \\
(2-105)\end{array}$} \\
\hline $\begin{array}{l}\text { Follow-up duration (mo) } \\
\text { Mean (range) }\end{array}$ & \multicolumn{2}{|c|}{$\begin{array}{l}60.2 \\
(4-115)\end{array}$} \\
\hline \multicolumn{3}{|l|}{ Complications: } \\
\hline Stroke & 3 & 23.1 \\
\hline Procedure-related & 1 & 7.7 \\
\hline Paraplegia & 3 & 23.1 \\
\hline Procedure-related & 0 & 0 \\
\hline Renal failure & 2 & 15.4 \\
\hline Sepsis & 3 & 23.1 \\
\hline Pneumonia & 3 & 23.1 \\
\hline Intra-abdominal infection & 1 & 7.7 \\
\hline Urinary tract infection & 1 & 7.7 \\
\hline Wound infection & 1 & 7.7 \\
\hline Delirium & 1 & 7.7 \\
\hline
\end{tabular}

aExcluding patients who did not survive to hospital discharge.

Although his recovery was complicated by an ischemic stroke, this patient survived to discharge and is symptom free during a 5 -year follow-up period. The other patient with grade-IV injury underwent replacement of the descending aorta through a clam shell incision, and did not survive.

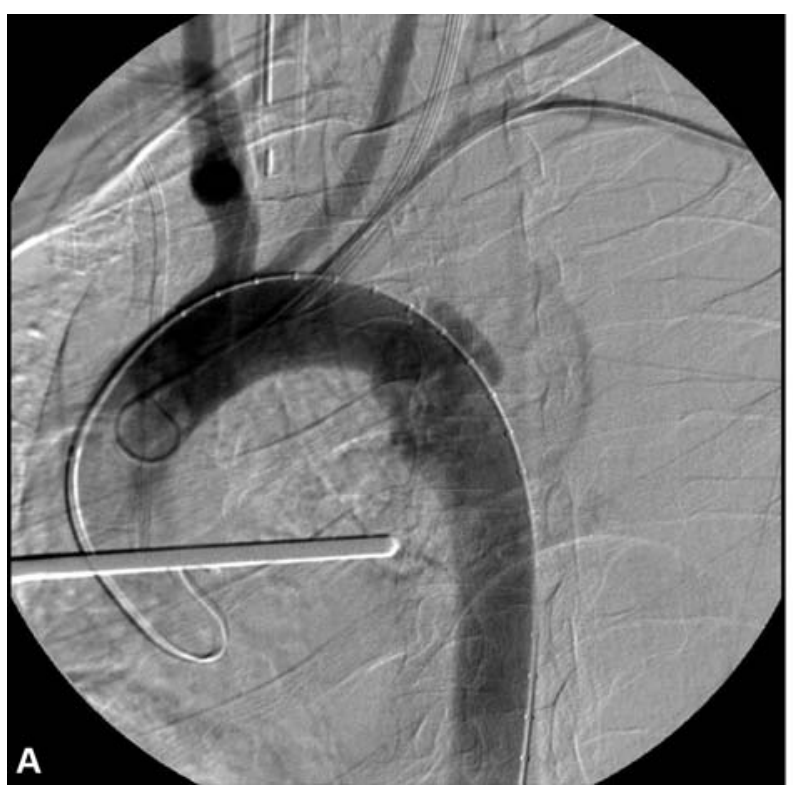

Table 4 Aortic injury characteristics

\begin{tabular}{|c|c|c|}
\hline Characteristic & $n$ & $\%$ \\
\hline \multicolumn{3}{|l|}{ Diagnostic modality: } \\
\hline Computed tomography angiogram & 13 & 100 \\
\hline \multicolumn{3}{|l|}{ Aortic injury location: } \\
\hline Isthmus & 12 & 92.3 \\
\hline Ascending aorta & 1 & 7.7 \\
\hline \multicolumn{3}{|l|}{ Society for Vascular Surgery grade: } \\
\hline I & 1 & 7.7 \\
\hline II & 6 & 46.2 \\
\hline III & 4 & 30.8 \\
\hline IV & 2 & 15.4 \\
\hline
\end{tabular}

Chest X-rays revealed mediastinal widening in all but one patient $(n=12)$. There was hemothorax in ten $(77 \%)$ patients, multiple rib fractures in seven (53.8\%), abdominal/pelvic organ injury in seven (53.8\%), and long bone fractures in six (46.2\%;-Table 5). None of the patients received craniotomy or maxillofacial reconstruction. A chest tube was inserted in ten (77\%) patients. Orthopaedic operations were performed in four (30.8\%) patients, laparotomy in three $(23.1 \%)$, and spinal surgery in one (7.7\%; - Table 6).

\section{Discussion}

A retrospective analysis of the National Trauma Data Bank revealed that incidence of BTAI among all trauma admissions is $0.3 \%{ }^{12}$ However, autopsy studies report thoracic aortic injuries to be present in 17 to $34 \%$ of blunt traumatic fatalities. ${ }^{13,14}$ The discrepancies between clinical and autopsy series are due to high mortality of BTAI. In fact, 75 to $85 \%$ of patients die before reaching a medical facility, and of those who reach

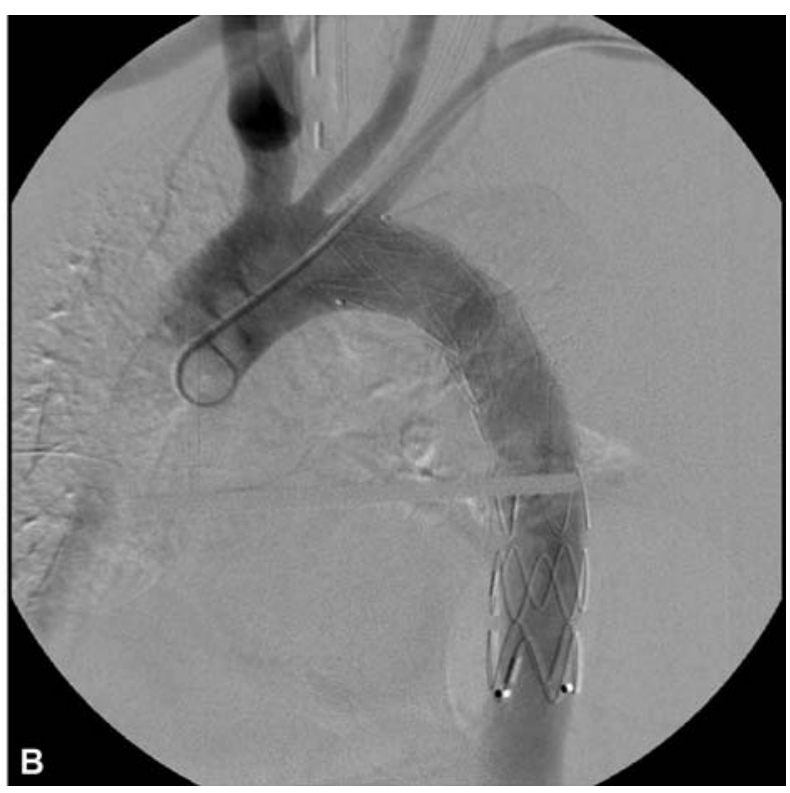

Fig. 3 (A) Arch aortogram demonstrating aortic isthmus pseudoaneurysm; (B) successful endovascular repair. 
Table 5 Concomitant injuries

\begin{tabular}{|l|l|l|}
\hline Injury type & $\mathbf{n}$ & $\%$ \\
\hline Head injury & 3 & 23.1 \\
\hline Maxillofacial injury & 3 & 23.1 \\
\hline Multiple rib fractures & 7 & 53.8 \\
\hline Flail chest & 1 & 7.7 \\
\hline Mediastinal widening & 12 & 92.3 \\
\hline Hemothorax & 10 & 77 \\
\hline Pneumothorax & 5 & 38.5 \\
\hline Pulmonary contusion & 5 & 38.5 \\
\hline Blunt myocardial injury & 1 & 7.7 \\
\hline Cardiac tamponade & 2 & 15.4 \\
\hline Diaphragm rupture & 1 & 7.7 \\
\hline Abdominal/pelvic organ injury & 7 & 53.8 \\
\hline Spinal cord injury & 2 & 15.4 \\
\hline Long bone fracture & 6 & 46.2 \\
\hline Sternal fracture & 1 & 7.7 \\
\hline Pelvic fracture & 5 & 38.5 \\
\hline Cervical spine injury & 1 & 7.7 \\
\hline Thoracic spine injury & 4 & 30.8 \\
\hline Lumbar spine injury & 3 & 23.1 \\
\hline
\end{tabular}

Table 6 Additional interventions

\begin{tabular}{|l|l|l|}
\hline Intervention & $\boldsymbol{n}$ & $\%$ \\
\hline Craniotomy & 0 & 0 \\
\hline Maxillofacial reconstruction & 0 & 0 \\
\hline Chest tube insertion & 10 & 77 \\
\hline Laparotomy & 3 & 23.1 \\
\hline Spinal surgery & 1 & 7.7 \\
\hline Orthopaedic surgery & 4 & 30.8 \\
\hline
\end{tabular}

hospital alive, $50 \%$ die before aortic repair can be performed. ${ }^{1-3}$ This high mortality rate explains why our high-volume tertiary cardiovascular surgery center observed so few BTAI cases over a period of 10 years. Besides, patients were referred for the sole purpose of aortic intervention, so we did not encounter many patients with minimal aortic injuries. Our study population included only one (7.7\%) patient with grade-I aortic injury, whereas a recent multicenter retrospective study which gathered data from nine level- 1 trauma centers reported $24.6 \%$ of BTAI patients had grade-I injuries. ${ }^{1}$ Of note, this patient was treated nonoperatively, and developed a late concomitant aortic pseudoaneurysm and coarctation very similar to a case previously reported. ${ }^{15}$

All-cause in-hospital mortality among our study population was 15.4 with $7.7 \%$ being aortic-related. These results are consistent with large multicenter retrospective studies. ${ }^{1,6,16}$ The only patient who died primarily of aortic injury was referred from a trauma center with a grade-IV isthmus injury. The 43-year-old male arrived in extremis with cardiac tamponade. His GCS was 3, and blood pressure was 60/ $30 \mathrm{~mm} \mathrm{Hg}$. An emergency sternothoracotomy was performed because appropriate stent graft could not be made immediately available. The duration between his initial presentation to the trauma center and emergency operation in our center reached 11 hours. This patient's prognosis could have been better if the aortic intervention was performed at the initial trauma center. Unfortunately, most trauma centers in our country were not equipped with endovascular capabilities as of 2019. Considering the high mortality rate associated with BTAI, more trauma centers need to adapt endovascular approaches.

Among patients treated primarily with TEVAR $(n=10)$, device-related complications occurred in one (10\%). The 37-year-old motorcycle collision victim presented with aortic isthmus pseudoaneurysm, severe head injury, and left hemothorax. Aortic diameter proximal to injury was $22.1 \mathrm{~mm}$. A $26 \mathrm{~mm} \times 150 \mathrm{~mm}$ endograft was implanted obtaining adequate proximal and distal seal. LSA origin was not covered. Free rupture occurred at the postoperative hour 8 , manifesting as hemodynamic collapse and excessive bleeding through the chest tube which was previously inserted for hemothorax. An emergent replacement of the descending aorta was performed through a left posterolateral thoracotomy using left heart bypass. He was discharged to home care with sequelae from head injury. This patient, along with the previously mentioned patient who underwent salvage open repair, demonstrates the fact that every center performing endovascular repair for BTAI should be experienced in open cardiovascular techniques.

Procedure-related stroke and paraplegia rates ( 7.7 and 0\%, respectively) in the present study are similar to previous reports. ${ }^{1,6,10,16-19}$ The only patient with a postoperative stroke was the patient who underwent Bentall's procedure. ${ }^{20}$ We did not observe postoperative stroke or paraplegia following TEVAR in our series. Due to the natural location of isthmus injuries, a considerable number of patients need LSA coverage during TEVAR. While others report lower rates of 30 to $40 \%$, coverage of LSA origin was needed in $70 \%(7 / 10)$ of our TEVAR patients. ${ }^{11,21}$ None of these patients developed subclavian steal syndrome, posterior stroke or left arm ischemia. We perform routine imaging to assess vertebral artery dominance and the circle of Willis in our center. Clinical practice guidelines of the SVS suggest selective revascularization of the LSA. Demetriades and colleagues ${ }^{6}$ reported only two cases who needed carotid to subclavian artery bypass among their experience of 125 BTAI patients treated with TEVAR.

Delayed repair of BTAI has been shown to improve mortality. ${ }^{5,9,18,22,23}$ We performed delayed repair in six patients and early repair in another six. One patient died in each group. Mean ISS of delayed repair group was 28.8 (range, 1636 ) versus 35.2 (range, 26-48) in the early repair group. All patients in the delayed repair group had grade-II injuries, whereas all patients in the early repair group had grade III and IV injuries. 


\section{Conclusion}

BTAI is a rare but highly fatal condition. TEVAR offers good early and midterm results for the treatment of BTAI. LSA coverage can be performed without major complications.

\section{Note}

A.C.T. currently works at the Department of Cardiovascular Surgery, Kartal Dr. Lutfi Kirdar Training and Research Hospital, Istanbul, Turkey.

\section{Funding}

None.

\section{Conflict of Interest}

The authors declare no conflict of interest related to this article.

\section{Acknowledgments}

None.

\section{References}

1 DuBose JJ, Leake SS, Brenner M, et al; Aortic Trauma Foundation. Contemporary management and outcomes of blunt thoracic aortic injury: a multicenter retrospective study. J Trauma Acute Care Surg 2015;78(02):360-369

2 Kenel-Pierre S, Ramos Duran E, Abi-Chaker A, et al. The role of heparin in endovascular repair of blunt thoracic aortic injury. J Vasc Surg 2019;70(06):1809-1815

3 Hasjim BJ, Grigorian A, Barrios C Jr., et al. National trends of thoracic endovascular aortic repair versus open thoracic aortic repair in pediatric blunt thoracic aortic injury. Ann Vasc Surg 2019;59:150-157

4 Parmley LF, Mattingly TW, Manion WC, Jahnke EJJr. Nonpenetrating traumatic injury of the aorta. Circulation 1958;17(06):1086-1101

5 Fox N, Schwartz D, Salazar JH, et al. Evaluation and management of blunt traumatic aortic injury: a practice management guideline from the Eastern Association for the Surgery of Trauma. J Trauma Acute Care Surg 2015;78(01):136-146

6 Demetriades D, Velmahos GC, Scalea TM, et al; American Association for the Surgery of Trauma Thoracic Aortic Injury Study Group. Operative repair or endovascular stent graft in blunt traumatic thoracic aortic injuries: results of an American Association for the Surgery of Trauma Multicenter Study.J Trauma 2008 ; 64(03):561-570, discussion 570-571

7 Kato N, Dake MD, Miller DC, et al. Traumatic thoracic aortic aneurysm: treatment with endovascular stent-grafts. Radiology 1997;205(03):657-662
8 Scalea TM, Feliciano DV, DuBose JJ, Ottochian M, O'Connor JV, Morrison JJ. Blunt thoracic aortic injury: endovascular repair is now the standard. J Am Coll Surg 2019;228(04):605-610

9 Demetriades D, Velmahos GC, Scalea TM, et al. Blunt traumatic thoracic aortic injuries: early or delayed repair-results of an American Association for the Surgery of Trauma prospective study. J Trauma 2009;66(04):967-973

10 Azizzadeh A, Keyhani K, Miller CC III, Coogan SM, Safi HJ, Estrera AL. Blunt traumatic aortic injury: initial experience with endovascular repair. J Vasc Surg 2009;49(06):1403-1408

11 Lee WA, Matsumura JS, Mitchell RS, et al. Endovascular repair of traumatic thoracic aortic injury: clinical practice guidelines of the Society for Vascular Surgery. J Vasc Surg 2011;53(01): 187-192

12 Arthurs ZM, Starnes BW, Sohn VY, Singh N, Martin MJ, Andersen CA. Functional and survival outcomes in traumatic blunt thoracic aortic injuries: an analysis of the National Trauma Databank. J Vasc Surg 2009;49(04):988-994

13 Williams JS, Graff JA, Uku JM, Steinig JP. Aortic injury in vehicular trauma. Ann Thorac Surg 1994;57(03):726-730

14 Teixeira PG, Inaba K, Barmparas G, et al. Blunt thoracic aortic injuries: an autopsy study. J Trauma 2011;70(01):197-202

15 Rangasetty UC, Raza S, Lick S, Uretsky BF, Birnbaum Y. Chronic pseudoaneurysm and coarctation of the aorta: a rare delayed complication of trauma. Tex Heart Inst J 2006;33(03):368-370

16 Fabian TC, Richardson JD, Croce MA, et al. Prospective study of blunt aortic injury: multicenter trial of the American Association for the Surgery of Trauma. J Trauma 1997;42(03):374-380, discussion 380-383

17 Estrera AL, Gochnour DC, Azizzadeh A, et al. Progress in the treatment of blunt thoracic aortic injury: 12-year single-institution experience. Ann Thorac Surg 2010;90(01):64-71

18 Estrera AL, Miller CC III, Guajardo-Salinas G, et al. Update on blunt thoracic aortic injury: fifteen-year single-institution experience.J Thorac Cardiovasc Surg 2013;145(3, suppl):S154-S158

19 Cardarelli MG, McLaughlin JS, Downing SW, Brown JM, Attar S, Griffith BP. Management of traumatic aortic rupture: a 30-year experience. Ann Surg 2002;236(04):465-469, discussion 469-470

20 Topcu AC, Ciloglu U, Bolukcu A, Dagsali S. Management of traumatic aortic and splenic rupture in a patient with ascending aortic aneurysm. Ann Thorac Surg 2016;102(02):e81-e82

21 McBride CL, Dubose JJ, Miller CC III, et al. Intentional left subclavian artery coverage during thoracic endovascular aortic repair for traumatic aortic injury. J Vasc Surg 2015;61(01):73-79

22 Marcaccio CL, Dumas RP, Huang Y, Yang W, Wang GJ, Holena DN. Delayed endovascular aortic repair is associated with reduced inhospital mortality in patients with blunt thoracic aortic injury. J Vasc Surg 2018;68(01):64-73

23 Akhmerov A, DuBose J, Azizzadeh A. Blunt thoracic aortic injury: current therapies, outcomes, and challenges. Ann Vasc Dis 2019; 12(01):1-5 